\title{
Regulación española sobre prevención y control integrado de la contaminación
}

\section{Victor Manteca Valdelande}

Doctor en Derecho

En este trabajo se hace una exposición de la normativa española sobre prevención y control integrado de la contaminación que es consecuencia de la normativa sobre contaminación y medio ambiente aprobada por las instituciones comunitarias, el nuevo sistema de regulación incluye aspectos como la autorización de emisión integrada que su ponen una notable evolución en el ordenamiento administrativo y medioambiental.

\section{INTRODUCCION}

La Ley 16/2002 de 1 de julio de prevención y control de la contaminación ${ }^{1}$ es un texto de suma importancia para nuestro ordenamiento, pues siguiendo la Directiva comunitaria 96/61/CE introduce una norma ambiental de carácter horizontal con el fin de conseguir la coordinación de los organismos públicos competentes en materia de contaminación.

El ordenamiento medioambiental español se compone de normativas sectoriales que regulan diferentes aspectos. Así en lo que se refiere a la contaminación atmosférica e hidrológica, se encuentran reguladas de manera separada, así la primera mediante la Ley 32/1972 de 22 de diciembre de Protección del Medio ambiente atmosférico (LPAA) ${ }^{2}$ y la segunda mediante el

${ }^{1}$ BOE núm 157 de 2 de julio de 2002.

${ }^{2}$ Ley 38/1972 de 22 de diciembre de Protección del medio ambiente atmosférico (BOE núm. 309 de 26 de diciembre de 1972), desarrollada mediante Decreto 833/1975 de 6 de febrero. El contenido de este Decreto fue adaptado a la normativa de las Comunidades Europeas por las siguientes normas:

1) En lo relativo a la presencia en el aire de contaminación por dióxido de azufre y partículas, mediante el Real Decreto 1663/1985 de 1 de agosto, parcialmente modificado por el R.D. 1154/1986 de 11 de abril (BOE núm. 146 de 19.6.1986) y por el R.D. 1321/1992 de 30 de octubre (BOE núm. 289 de 2.12.1992, corrección de erratas en BOE núm. 29 de 3.2.1993). 
Texto Refundido de la Ley de Aguas (LA) ${ }^{3}$. Ambas leyes se encuentran desarrolladas por normativa reglamentaria cuyo contenido no va ser objeto de examen en estas líneas.

La contaminación atmosférica tiene en el ordenamiento español actual dos instrumentos de protección, el primero de carácter eminentemente preventivo, consiste en el establecimiento de niveles de emisión e inmisión y el segunda, que se pone en marcha en el momento en que la contaminación se ha producido y conlleva importantes consecuencias ya sea porque afecta a un área especialmente sensible o por las peculiares circunstancias de alarma concurrentes y consiste en la puesta en marcha de dispositivos correctores.

2) En lo que se refiere a las normas de calidad del aire para el dióxido de nitrógeno y el valor límite para el plomo contenido en la atmósfera, mediante el real Decreto 717/1987 de 27 de mayo (BOE núm. 135 de 6.6.1987) que adecuo el decreto 833/1975 a las Directivas 85/203/CEEE de 7.3.1985 y 82/884/CEE de 3.12.1982.

3) Por Real Decreto 646/1991 de 22 de abril (BOE núm. 99 de 25.4.1991) se establecieron nuevas normas sobre limitación de emisiones a la atmósfera de determinados agentes contaminantes procedentes de grandes instalaciones de combustión como había determinado la Directiva 94/66/CE, se desarrolló mediante Orden de 26 de diciembre de 1995 (BOE núm. 312 de 30.12.1995) en lo relativo a centrales termoeléctricas.

4) Por Real Decreto 1088/1992 de 11 de septiembre (BOE núm. 235 de 30.9.1992) modificado por R.D. 1217/1997 de 18 de julio (BOE 189 de 8.8.1997, corrección de erratas en BOE núm. 15 de 17.1.1998) se establecieron normas sobre limitación de emisiones a la atmósfera de determinados agentes contaminantes procedentes de instalaciones de incineración de residuos municipales.

5) En cuanto a la contaminación atmosférica por ozono el Real Decreto 1494/1995 de 8 de septiembre (BOE núm. 230 de 26.9.1995) adaptó el contenido del Decreto 833/1975 a la Directiva 92/72/CEE.

6) Por Real Decreto 2102/1996 de 20 de septiembre (BOE núm. 259 de 26.10.1996) se reguló el control de emisión de compuestos orgánicos volátiles (COV) resultantes de almacenamiento y distribución de gasolina desde terminales a las estaciones de servicio. Sobre incineración de residuos peligrosos ver también R.D. 1217/1997 de 18 de julio (BOE núm. 189 de 8.8.1997).

Finalmente la Ley 4/1998 de 3 de marzo (BOE núm. 54 de 4.3.1998) por la que se establece el régimen sancionador previsto en el Reglamento CE 3093/1994 del Consejo de 15 de diciembre, relativo a sustancias que agotan la capa de ozono.

${ }^{3}$ Aprobado por Real Decreto legislativo 1/2001 de 20 de julio (BOE núm. 176 de 24.7.2001. Ley 29/1985 de 2 de agosto de Aguas BOE núm. 189 de 8.8.1985, corrección de errores en BOE núm. 243 de 10.10.1985. El Reglamento del Dominio Público Hidráulico se aprobó por Real Decreto 849/1986 de 11 de abril (BOE núm. 103 de 30.4.1986; corrección de errores en BOE núm. 157 de 2.7.1986), modificado por R.D. 1315/1992 de 30 de octubre (BOE núm. 288 de 1.12.1998), por R.D. 419/1993 de 26 de marzo (BOE núm. 89 de 14.4.1993) y por R.D. 1771/1994 de 5 de agosto (BOE núm. 198 de 19.8.1994). Ver Orden de 11 de mayo de 1988 (BOE núm. 124 de 24.5.1988), modificada por las Ordenes de 15 de octubre de 1990 (BOE núm. 254 de 23.10.1990) y de 30 de noviembre de 1994 (BOE 298 de 14.12.1998), sobre características básicas de calidad que han de ser mantenidas en las corrientes de agua superficiales cuando sean destinadas a la producción de agua potable. 
Las determinaciones generales y excepcionales contenidas en la LPAA, como hemos dicho, han sido desarrolladas por un grupo de normas que abordan la regulación de la contaminación atmosférica desde una perspectiva esencialmente preventiva, que toma en consideración la fuente de producción de la misma. Dada la multiplicación de estas fuentes y la comprobación científica de la intensidad perjudicial de ciertos de sus efectos para la atmósfera, esta normativa ha sido muy abundante, siendo los principales aspectos sobre los que ha incidido los de establecimientos industriales y vehículos automóviles.

Respecto al aspecto hidrológico recordemos que la Ley de Aguas supuso el cambio de concepción de un modelo de política hidráulica consistente en la explotación intensiva del agua. La Ley de 1985 regula una explotación del agua compatible con la preservación de su función ecológica y la conservación del entorno. La Ley aborda la calidad de las aguas tratando de implicar a todos los agentes interesados y persiguiendo el principio de quien contamina paga favoreciendo la competitividad de quienes apliquen tecnologías no contaminantes. Con carácter general prohibe la Ley las actividades que puedan constituir un peligro para la contaminación de las aguas o degradación del dominio hidráulico (vertidos directos o indirectos, acumulación de residuos sólidos, escombros o substancias, etc).

En materia de contaminación de los suelos hemos de hacer referencia a la normativa sobre residuos, cuya puesta en marcha se está consiguiendo gracias al empeño de todas las administraciones implicadas.

\section{REGULACION COMUNITARIA DE LA CONTAMINACION AM- BIENTAL}

En el ámbito comunitario hay que recordar que desde finales de los años sesenta la protección y conservación del medio ambiente ha sido una de las principales inquietudes de la Comunidad Europea hasta el punto que ha terminado por incorporarse a los Tratados como una auténtica Política Comunitaria cuyo principal objetivo es el de la prevención, de acuerdo con las previsiones de los sucesivos programas de acción comunitarios en materia de medio ambiente y desarrollo sostenible.

El Quinto Programa adoptado en 1992 tuvo aplicación hasta el año 2000. Se fundamentó, principalmente en el concepto del desarrollo sostenible formulado el Informe Brutland. Hay toda una serie de principios básicos, interna- 
cionalmente aceptados, que conforman el modelo de desarrollo sostenible, como el derecho de las personas a una vida saludable, el derecho de los Estados a aprovechar ordenadamente sus recursos naturales, la cooperación internacional, la erradicación de la pobreza, el fomento de la participación ciudadana, la prevención, la actuación en origen, etc.

Este Programa incidió directamente sobre las estrategias de desarrollo de la Comunidad, por ello se le concedió un plazo de duración más amplio que los anteriores y trataba de conseguir que el mundo occidental asumiera la necesidad de regular el crecimiento económico y dar un nuevo contenido ala calidad de vida a través de un modelo que no pusiera en crisis la propia existencia de los recursos en los que se basa la vida en la tierra. Para ello fueron seleccionados cinco sectores económicos de importancia estratégica en los que había que introducir profundos cambios.

Los diversos instrumentos de actuación contemplados por este Programa (legislativos, económicos, fiscales) se irían introduciendo de manera escalonada con el fin de lograr un cambio de tendencia de largo alcance frente al creciente deterioro del ambiente existente.

Las líneas estratégicas generales de crecimiento para los grandes sectores económicos implicados se describían en el Programa de este modo:

Sector Industrial: Se presentó un planteamiento en que se combinaba, la normativa ambiental, con medidas que incentivaban la colaboración y autorregulación del sector. De modo coordinado en los diferentes puntos de la cadena de investigación, procesado, fabricación, comercialización y eliminación de residuos. A diferencia de los anteriores Programas que únicamente contemplaban la aplicación de medidas en fases concretas como la contaminación del proceso, y residuos finales.

Para ello se trató de convencer a los agentes industriales, acerca de los beneficios que reportaría la adopción de una política de desarrollo sostenible, cambiando sus criterios coste/beneficio en un plazo corto o medio.

Por otra parte se consideraba que la sensibilización y los criterios de selección de los consumidores constituyen un factor clave para el fomento de los procesos de fabricación de productos ecológicos.

Por todo ello, se establecieron una serie de medidas: 
- Aumentar el diálogo con la industria y favorecer la participación de la opinión pública, facilitando el acceso a la información medioambiental.

- Realizar evaluaciones de impacto ambiental de las actividades industriales con objeto de perfeccionar la planificación de procesos.

- Mejorar la gestión de los residuos industriales: reutilización, reciclaje y retorno.

- Fomentar acuerdos, de carácter voluntario, en el sector industrial.

- Gestión adecuada de los recursos, racionalizando el consumo y la competitividad.

- Control ambiental de los productos finales mediante etiquetas ecológicas comunitarias.

Sector energético: Los principales objetivos energéticos en el Quinto Programa fueron la reducción de la contaminación causante de la lluvia ácida y de los gases causantes del efecto invernadero. Para conseguir esto, se contemplaba una serie de medidas, como el aumento del rendimiento energético en los sectores productivo y doméstico, introducción de nuevas tecnologías, aumento de la seguridad nuclear o la promoción de energías alternativas.

Sector del Transporte: Este programa se centró en la reducción de dos problemas fundamentales: el alto nivel de las emisiones contaminantes y el grado de contaminación acústica. El caballo de batalla se encontraba en el excesivo tamaño del transporte por carretera que además se encuentra en fase de clara expansión.

Las medidas se orientaron en tres ámbitos fundamentales: Infraestructuras, Medios de transporte y combustibles utilizados y Comportamiento de los usuarios

Sector Agrario: Las tierras del cultivo, junto con las forestales, ocupan el $80 \%$ de la superficie de la Comunidad. Las mejoras tecnológicas han contribuido a la sobreexplotación. El Uso de pesticidas ha degradado el medio ambiente y la uniformidad genética de los animales ha derivado en la degeneración de algunas especies. Todo ello obliga a la adopción de una serie de medidas que se pueden resumir en la Conservación de la diversidad biológica y de los hábitats naturales; la reducción de los pesticidas y productos químicos y el est6ablecimiento de elementos favorecedores de la agricultura extensiva.

Sector turístico: La previsión de aumento turístico en las costas mediterráneas, afectará a la gestión del agua, al consumo de los recursos naturales y 
a la generación de residuos. Esto obliga a la adopción de una estrategia de sostenibilidad que incida en una serie de medidas como el control de usos del suelo, cumplimiento de las normas de vertido, mejora de la oferta turística promocionando servicios respetuosos con el medio ambiente o fomentando el turismo rural y cultural y también el transporte colectivo en este ámbito.

Para corregir estas disfunciones y aplicar las políticas medioambientales, se han desarrollado instrumentos de intervención, que pueden resumirse en los siguientes clases: Instrumentos legislativos y normativos, Instrumentos de mercado, Instrumentos horizontales, Instrumentos financieros o reguladores de las intervenciones financieras de la Unión Europea.

El Programa de política medioambiental europea Hacia un desarrollo sostenible relativo al medio ambiente y al desarrollo sostenible se elaboró de manera paralela a la Agenda 21. Dicho programa traza un nuevo camino mediante la integración de políticas, leyes y proyectos en un programa global de reforma orientado a un único objetivo: el desarrollo sostenible.

En este escenario una de las actuaciones más ambiciosas puestas en marcha en el seno de la Unión Europea para reforzar el principio de prevención en el funcionamiento de las instalaciones industriales mas contaminantes fue la aprobación de la Directiva 1996/61/CE del Consejo de 24 de septiembre ${ }^{4}$, relativa a la prevención y al control integrado de la contaminación, mediante el que se establecen medidas para evitar o reducir las emisiones de estas actividades en la atmósfera, el agua y el suelo, incluidos los residuos para poder alcanzar un nivel elevado de protección del medio ambiente considerado en su conjunto. También se incorpora la Directiva 1999/13 CE del Consejo de 11 de marzo ${ }^{5}$, relativa a las limitaciones de las emisiones de compuestos orgánicos volátiles derivados del uso de disolventes en determinadas actividades e instalaciones. Para hacer efectiva la prevención y el control integrado la Directiva establece la necesidad de obtención de autorizaciones para la puesta en marcha de una serie de instalaciones industriales que deberá concederse de manera coordinada cuando sean varias las autoridades que intervengan en el procedimiento. En esta autorización se fijarán las condiciones ambientales exigidas para la explotación de las instalaciones especificando valores límites de emisión de sustancias contaminantes.

\footnotetext{
${ }^{4}$ DOCE L 257/1996 de 10.10.1996.

${ }^{5}$ DOCE L 85 de 29.3.1999.
} 


\section{LA LEY DE PREVENCION Y CONTROL INTEGRADOS DE LA CONTAMINACION}

Para la incorporación de la Directiva al Ordenamiento español se ha aprobado la Ley de prevención y control integrados de la contaminación, cuya presentación realizamos en las presentes líneas.

El contenido de esta norma tiene un claro carácter preventivo y de protección del medio ambiente en su conjunto con la finalidad de evitar o al menos reducir, la contaminación de la atmósfera, el agua y el suelo.

La puesta en vigor de esta Ley exige un enorme esfuerzo de adaptación tecnológica para la industria española y su cumplimiento exigirá un nivel de coordinación hasta ahora desconocido en nuestro país dado que sus contenidos atañen a todas las administraciones públicas.

El objeto de este texto consiste en evitar o en los casos en que esto no sea posible, reducir y controlar la contaminación de la atmósfera, del agua y del suelo mediante el establecimiento de un sistema de prevención y control integrado de la contaminación para poder alcanzar un nivel de protección elevada del medio ambiente en su conjunto.

La Ley será aplicable a las instalaciones de titularidad pública o privada en las que se desarrolle alguna de las actividades enumeradas dentro de las siguientes categorías:

- Instalaciones de combustión.

- Producción y transformación de metales.

- Industrias minerales.

- Industrias químicas.

- Gestión de residuos

- Industria de papel y de cartón.

- Industria textil.

- Industria del cuero.

- Industrias agroalimentarias y explotaciones ganaderas.

- Consumo de disolventes orgánicos.

- Industria del carbono.

El texto incluye la definición de la contaminación establecida en la Directiva 96/61/CE la introducción directa o indirecta, mediante la actividad humana, de sustancias, vibraciones, calor o ruido en la atmósfera, el agua o el suelo, que puedan 
tener efectos perjudiciales para la salud humana o la calidad del medio ambiente, o que puedan causar daños a los bienes materiales o deteriorar o perjudicar el disfrute u otras utilizaciones legítimas del medio ambiente.

Bajo el rótulo Valores límites de emisión y mejores técnicas disponibles, se introducen en el Título II los aspectos más importantes del contenido de la Directiva citada. Estableciéndose que en la autorización ambiental integrada deberán establecerse los valores límites de emisión de sustancias contaminantes.

También se faculta al Gobierno y a las Comunidades Autónomas para que establezcan reglamentariamente valores límite de emisión, así como parámetros o medidas técnicas que los sustituyan, para determinadas sustancias o categorías específicas de instalaciones. Llevando a efecto el concepto de integración que pretende la norma se regulan los mecanismos de intercambio de información entre el Ministerio de Medio ambiente y las Comunidades Autónomas sobre las principales emisiones contaminantes, sus focos y las mejores técnicas disponibles.

\section{AUTORIZACION AMBIENTAL INTEGRADA}

El Título III desarrolla el régimen jurídico de la autorización ambiental integrada a que se somete la construcción, montaje, explotación o traslado, así como la modificación sustancial de las instalaciones que desarrollen alguna de las actividades enumeradas.

La Ley considera autorización ambiental integrada a la resolución del órgano competente de la Comunidad Autónoma en la que se ubique la instalación de referencia, por la cual se permite, al efecto de protección del medio ambiente y de la salud de las personas. La explotación de aquella bajo determinadas condiciones que garanticen el cumplimiento de las disposiciones de la Ley.

La autorización ambiental integrada podrá ser válida para una o más instalaciones que tengan la misma ubicación y sean explotadas por el mismo titular 6 .

\footnotetext{
${ }^{6}$ Se entiende por instalación cualquier unidad técnica fija en donde se desarrolle una o más actividades industriales enumeradas en el anejo 1 de la Ley así como cualesquiera otras directamente relacionadas con aquellas que guarden relación de índole técnica con las actividades llevadas a cabo en dicho lugar y puedan tener repercusiones sobre las emisiones y la contaminación.

Titular es cualquier persona física o jurídica que explote o posea una instalación.
} 
El fin de la autorización ambiental integrada consiste en establecer las condiciones que garanticen el cumplimiento de la Ley por las instalaciones ${ }^{7}$, disponer de un sistema de prevención y control de contaminación que integre en un solo acto administrativo todas las autorizaciones ambientales existentes en materia de producción y gestión de residuos sólidos, líquidos y gaseosos ${ }^{8}$.

Desde un punto de vista formal, el otorgamiento de la autorización ambiental integrada estará precedido de las autorizaciones industriales específi$\operatorname{cas}^{9}$ y de la Licencia municipal de actividades clasificadas ${ }^{10}$ y se otorgará sin perjuicio de las demás autorizaciones que deban exigirse.

La solicitud de la autorización ambiental integrada deberá presentarse ante el órgano de la Comunidad Autónoma en cuyo ámbito territorial se ubique la instalación ${ }^{11}$ contener una serie de requisitos mínimos:

1) El Proyecto básico que deberá incluirá memoria en la que se describa concretamente la actividad, instalaciones, procesos productivos y tipo de producto cuya autorización se solicita y su alcance.

${ }^{7}$ A través de un procedimiento de coordinación de las diferentes Administraciones Públicas que deban intervenir en la autorización para agilizar trámites y reducir las cargas administrativas de los particulares. (Artículo 11).

\footnotetext{
${ }^{8}$ Incluida la incineración de residuos municipales y peligrosos y, en su caso, las de vertido de residuos; de vertidos a las aguas continentales; incluidos los vertidos al sistema integral de saneamiento, y vertidos desde la tierra al mar, así como las determinaciones de carácter ambiental en materia de contaminación atmosférica, incluidas las referentes a los compuestos orgánicos volátiles. (Artículo 11).
}

${ }^{9}$ Enumeradas en el artículo 3 b de la Ley.

10 Regulada por el reglamento de actividades molestas, insalubres, nocivas y peligrosas aprobada por Decreto 2414/1961 de 20 de diciembre (BOE núm. 292 de 7.12.1961 corrección errores BOE núm. 57 de 15.3.1962).

11 Puede presentarse asimismo en los lugares que enumera la Ley 30/1992 de 26 de noviembre de Régimen jurídico de las Administraciones Públicas y del Procedimiento Administrativo Común.

Artículo 38-4 Las solicitudes, escritos y comunicaciones que los ciudadanos dirijan a los órganos de las Administraciones Públicas podrán presentarse:

- En los Registros de los órganos administrativos a que se dirijan.

- En los Registros de cualquier órgano administrativo que pertenezca a la Administración General del estado, de las Comunidades Autónomas o de alguna de las entidades que integran la Administración Local si se hubiera suscrito convenio en este sentido.

- En las Oficinas de Correos.

- En las Representaciones diplomáticas u Oficinas consulares de España en el extranjero.

- En cualquier otro que establezcan las disposiciones vigentes. 
Esta memoria descriptiva deberá ir acompañada de la documentación exigida para la obtención de la licencia municipal de actividades clasificadas. Así al solicitar la licencia municipal si se trata de establecer una actividad que pueda hallarse comprendida entre las molestas, insalubres, nocivas y peligrosas se deberá acompañar la siguiente documentación: Proyecto técnico y Memoria descriptiva en que se detallen las características de la actividad, su posible repercusión sobre la sanidad ambiental y los sistemas correctores que se propongan utilizar, expresando su grado de eficacia y garantía de seguridad ${ }^{12}$.

2) Informe del Ayuntamiento en cuyo territorio se ubique la instalación que acredite la compatibilidad del proyecto con el planeamiento urbanístico, que deberá ser emitido en el plazo máximo de treinta días ${ }^{13}$. Si el informe fuera negativo, el órgano competente dictará resolución motivada poniendo fin al procedimiento y archivando las actuaciones.

3) La documentación exigida por la normativa reguladora de aguas para la autorización de vertidos a las aguas continentales y por la legislación de costas para la autorización de vertidos desde tierra al mar ${ }^{14}$.

4) La determinación de los datos que a juicio del solicitante, gocen de confidencialidad de acuerdo con las disposiciones vigentes.

5) Cualquier otra documentación que acredite el cumplimiento de los requisitos exigidos por la normativa aplicable, incluyendo la relativa a fianzas o seguros obligatorios y en fin cualquier otra documentación o información que determine la legislación vigente.

La solicitud deberá ir acompañada de un resumen de la documentación presentada con el fin de facilitar la comprensión en el trámite de información pública.

En los casos de evaluación de impacto ambiental, de actuaciones en materia de medidas de control por riesgo de accidente grave al intervenir sus-

\footnotetext{
12 Artículo 29 del Reglamento de actividades molestas, insalubres, nocivas y peligrosas aprobado por Decreto 2414/1961 de 30 de diciembre (BOE núm. 292 de 7.12.1961), ver Decreto 3494/1964 de 5 de noviembre.

${ }^{13} \mathrm{Si}$ no fuera emitido, el informe se suplirá con una copia de la solicitud del mismo artículo 15 de la Ley.

${ }^{14} \mathrm{Si}$ se trata de vertidos a las aguas continentales de cuencas intercomunitarias, esta documentación será inmediatamente remitida al organismo de cuenca por el órgano autonómico ante el que se haya presentado la solicitud, a fin de que manifieste si es precisos requerir al solicitante que subsane la falta o acompañe los documentos preceptivos.
} 
tancias peligrosas y en aquellos otros casos previstos por la Ley la solicitud de autorización ambiental integrada deberá incluir además el estudio de impacto ambiental y demás documentación exigida por la normativa aplicable sobre este extremo ${ }^{15}$.

Una vez presentada la solicitud con la documentación indicada, el procedimiento seguido consistirá en la apertura de un periodo de información pública no inferior a treinta días ${ }^{16}$ que será común para aquellos procedimientos cuyas actuaciones se han integrado en este de autorización ambiental integrada así como, en su caso para los que señala la Ley como autorizaciones sustantivas ${ }^{17}$.

Concluido el periodo de información pública se solicitará informe a los diferentes órganos, entre ellos el Ayuntamiento ${ }^{18}$ y el Organismo de cuenca ${ }^{19}$, que deban pronunciarse sobre las diferentes materias de su competencia mediante remisión de una copia del expediente.

Elaborada la evaluación ambiental del proyecto en su conjunto se presentará propuesta de resolución tras un trámite de audiencia a los interesados.

15 Real Decreto Legislativo 1302/1986 sobre evaluación de impacto ambiental (BOE núm. 155 de 30.6.1996) modificado por Real Decreto-Ley 9/2000 de 6 de octubre (BOE núm. 241 de 7.10.2000).

${ }^{16}$ Quedan exceptuados de la apertura de este periodo los expedientes a los que la normativa vigente atribuya carácter confidencial a este efecto.

17 El artículo 3 b de la Ley define Autorizaciones sustantivas: las autorizaciones de industrias o instalaciones industriales que estén legal o reglamentariamente sometidas a autorización administrativa previa de conformidad con el artículo 4 de la Ley 21/1992 de 16 de julio de Industria. En particular tendrán esta consideración, las autorizaciones establecidas en la Ley 54/1997 de 27 de noviembre del sector eléctrico; en la Ley 34/1998 de 7 de octubre del sector de Hidrocarburos y en el capítulo de la Ley Orgánica 1/1992 de 21 de febrero sobre protección de la seguridad ciudadana, en lo referente a las instalaciones químicas para la fabricación de explosivos.

${ }^{18}$ El Ayuntamiento en cuyo territorio se ubique la instalación, emitirá en el plazo de treinta días informe acerca de la adecuación de la misma referido a todas las materias de su competencia. En caso de que este informe no fuera emitido en plazo se proseguirán las actuaciones, debiendo valorarse el informe emitido fuera de plazo.

${ }^{19}$ Cuando la actividad sometida a autorización precise permiso de vertido al dominio público hidráulico de cuencas intercomunitarias, el organismo de cuenca deberá emitir informe vinculante en plazo de seis meses, acerca de la admisibilidad del vertido, determinar las características del mismo y las medidas correctoras a fin de preservar el buen estado de las aguas. 
La Resolución pondrá fin al procedimiento en el plazo máximo de diez meses. Transcurrido dicho plazo sin haberse notificado resolución expresa, la solicitud podrá entenderse desestimada ${ }^{20}$.

La autorización ambiental integrada se otorgará sin perjuicio de las autorizaciones o concesiones que deban ser exigidas para la ocupación o utilización del dominio público por la normativa reguladora de dicha materia $^{21}$.Quedan exceptuados de esto las autorizaciones de vertidos alas aguas continentales y al dominio público marítimo-terrestre, desde tierra al mar, que se encuentran incluidos en la nueva autorización ambiental integrada.

El contenido de la autorización ambiental, incluirá como mínimo los siguientes aspectos:

1) Los valores límite de emisión en cada caso basados en las mejoras técnicas disponibles para las sustancias contaminantes en especial para las enumeradas en el anejo $3^{22}$ que puedan ser emitidas por la instalación así como los parámetros o medidas técnicas equivalentes que los completen o sustituyan.

Para la determinación de estos valores límite de emisión ${ }^{23}$ deberá tenerse en cuenta la información suministrada por la Administración sobre mejoras técnicas disponibles ${ }^{24}$; las características técnicas de las

${ }^{20} \mathrm{El}$ órgano competente para otorgar la autorización ambiental integrada deberá notificar la resolución a los interesados, al Ayuntamiento donde se ubique la instalación, a los diferentes órganos que hubiesen emitido informes vinculantes y, en su caso al organismo estatal competente para otorgar las autorizaciones sustantivas que señala el artículo 11-2.

Todos tienen derecho de acceso a las resoluciones y las comunidades Autónomas darán publicidad a las resoluciones en sus respectivos Boletines Oficiales. (Artículo 23).

21 Texto refundido de la Ley de Aguas y normativa de desarrollo arriba citada y Ley 2271988 de 28 de julio de Costas (BOE núm. 181 de 28.7.1988).

${ }^{22}$ El anejo 3 de la Ley establece la lista de las principales sustancias contaminantes que se tomarán obligatoriamente en consideración si son pertinentes para fijar valores limite de emisiones. En la atmósfera y en el agua.

23 Artículo 7 de la Ley.

${ }^{24}$ El artículo 8-1 de la Ley dispone que la Administración General del Estado suministrará a las Comunidades Autónomas la información que obre en su poder sobre las mejores técnicas disponibles, sus prescripciones de control y su evolución y, en su caso, elaborará guías sectoriales sobre las mismas y su aplicación para la determinación de los valores límite de emisión. 
instalaciones en donde se desarrolle alguna de las actividades industriales enumeradas en el anejo 1 de la Ley, su implantación geográfica y las condiciones locales del medio ambiente; los planes nacionales aprobados, para dar cumplimiento a compromisos en la normativa comunitaria o en tratados internacionales; la incidencia de las emisiones en la salud humana potencialmente afectada y en las condiciones generales de la sanidad animal y los valores límites de emisión fijados por la normativa vigente.

2) Las condiciones que garanticen la protección del suelo y aguas subterráneas.

3) Los procedimientos y métodos que vayan a emplearse para la gestión de residuos generados por la instalación.

4) Las prescripciones que garanticen la minimización de la contaminación a larga distancia o transfronteriza.

5) Los sistemas para control y tratamiento de todo tipo de emisiones, fugas, fallos, etc, especificando el método de medición, su frecuencia y los sistemas de evaluación de mediciones.

6) También podrán incluirse situaciones de excepción en estos parámetros previa presentación por el solicitante de un plan de rehabilitación y proyecto de reducción de la contaminación.

La autorización ambiental integrada se otorgará por un plazo máximo de ocho años a cuyo término deberá ser renovada y en su caso actualizada por periodos sucesivos ${ }^{25}$. La autorización ambiental integrada podrá ser modificada de oficio sin necesidad de que medie solicitud en los siguientes casos:

a) Cuando se estime conveniente la revisión de los valores límite de emisión impuestos o la adopción de otros nuevos, debido a la contaminación producida por la instalación.

b) Si se considera posible reducir las emisiones contaminantes introduciendo cambios en las mejores técnicas disponibles sin imponer costes excesivos.

c) Cuando la propia seguridad de funcionamiento del proceso o actividad exija emplear otras técnicas.

d) Cuando el organismo de cuenca estime necesaria la revisión de la autorización en lo relativo al vertido de aguas al dominio público hi-

\footnotetext{
${ }^{25}$ Para la renovación el titular deberá solicitarla con una antelación mínima de diez meses antes del vencimiento del plazo de vigencia. Si vencido el plazo no se hubiese dictado resolución expresa sobre la renovación se entenderá estimada y consecuentemente renovada la autorización ambiental integrada en las condiciones anteriores.
} 
dráulico en cuencas intercomunitarias de acuerdo con la normativa reguladora en vigor $^{26}$.

e) Cuando lo requiera la normativa sectorial aplicable.

La modificación de una instalación sometida a autorización ambiental integrada podrá ser sustancial o no sustancial. La modificación será calificada como sustancial cuando tenga una incidencia notable sobre la seguridad, la salud de las personas y el medio ambiente en los siguientes aspectos:

- El tamaño y producción de la instalación.

- Los recursos naturales utilizados por ella.

- El consumo de agua y energía.

- El volumen, peso y tipología de los residuos generados.

- La calidad y capacidad regenerativa de los recursos naturales de las áreas geográficas que puedan verse afectadas.

- El grado de contaminación producido.

- El riesgo de accidentes.

- La incorporación o aumento en el uso de sustancias peligrosas.

Antes de realizar la modificación, debe comunicarse a la Administración que otorgó la autorización ambiental integrada acompañando los documentos justificativos si se trata de una modificación de carácter no sustancial el titular podrá llevarla acabo si la administración no se opone en el plazo de un mes, pero en caso de modificaciones sustanciales será preciso contar con una nueva autorización ambiental inegrada.

La Ley dedica un capítulo específico a la coordinación entre órganos administrativos del procedimiento de autorización ambiental ${ }^{27}$, en primer lugar coordinación con el procedimiento de evaluación de impacto ambiental y en segundo con el régimen aplicable en materia de actividades clasificadas:

A) En el primer caso cuando sea competencia de la Administración General del Estado la formulación de la declaración de impacto ambiental de conformidad con su normativa reguladora específica ${ }^{28}$ no

\footnotetext{
${ }^{26}$ En este caso el organismo de cuenca requerirá mediante informe vinculante al órgano competente para otorgar la autorización ambiental integrada para que inicie el procedimiento de modificación en un plazo máximo de veinte días.

27 Capítulo III del Título III Coordinación con otros mecanismos de intervención ambiental.

${ }^{28}$ Real Decreto Legislativo 1302/1986 de evaluación de impacto ambiental (BOE núm. 155 de 30.6.1986), modificado por el Real Decreto-Ley 9/2000 de 6 de octubre de modificación de (BOE núm. 241 de 7.10.2000).
} 
podrá otorgarse la autorización ambiental integrada, ni las autorizaciones sustantivas que enumera el artículo $3 \mathrm{~b}$ sin que previamente se haya dictado la declaración de impacto ambiental.

La declaración de impacto ambiental constituye el dictamen u opinión de la autoridad ambiental en el que se determinan las condiciones que deban establecerse en orden a la adecuada protección del medio ambiente y de los recursos naturales. En dicho pronunciamiento se determina la conveniencia o no de realizar la actividad proyectada y sometida a la declaración, y, en caso afirmativo, las condiciones que deban establecerse en orden a la adecuada protección del medio ambiente y los recursos naturales ${ }^{29}$.

Con respecto a esta materia la Ley dispone que tan pronto como la Administración competente en materia ambiental haya formulado la declaración de impacto ambiental o tras la resolución de discrepancias en su caso, remitirá una copia de la misma a los organismos encargados de otorgar las autorizaciones sustantivas que fueran exigibles ${ }^{30}$.

B) Respecto a las actividades clasificadas la Ley dispone que el procedimiento para la autorización ambiental integradas sustituirá al procedimiento para la obtención de la Licencia Municipal de actividades clasificadas $^{31}$ salvo en lo referente a la resolución definitiva de la autoridad municipal para la que resultará vinculante la resolución sobre la autorización ambiental integrada en los casos en que implique denegación de Licencias o imposición de medidas correctoras ${ }^{32}$. Sin perjuicio de la normativa autonómica de aplicación en materia de actividades clasificadas.

\section{CONTROL E INSPECCION}

Como corolario de eficacia la Ley establece un sistema de control e inspección a cargo de las Comunidades Autónomas que deberán adoptar las medidas oportunas para garantizar el cumplimiento de la Ley ${ }^{33}$.

${ }^{29}$ Real Decreto 1331/1988 de 30 de septiembre aprobó el Reglamento para la ejecución del Real Decreto Legislativo 1302/1986 sobre evaluación de impacto ambiental (BOE núm. 239 de 5.10.1988).

${ }^{30}$ Artículo 28 de la Ley.

${ }^{31}$ Regulado por el Decreto 2414/1961 de 30 de noviembre antes citado.

${ }^{32}$ Así como en todos los aspecto medioambientales recogidos en el artículo 22. Artículo 29 de la Ley.

${ }^{33}$ Sin perjuicio de la competencia estatal en materia de vertidos en cuencas intercomunitarias que estará a cargo de los correspondientes organismos de cuenca (Confederaciones Hidrográficas). 
La Ley, que se denomina de prevención y control integrado de la contaminación, constituye principalmente una normativa dirigida al control y por ello merece detenerse en el examen de esta actividad administrativa.

La potestad administrativa de control es aquella parte de la actividad administrativa cuyo objeto consiste, en funciones de comprobación o constatación del cumplimiento de la normativa vigente en una materia concreta, incluidas muy especialmente las condiciones y requisitos de orden técnico, consecuencia inherente de la imposición que a determinadas personas, actividades, instalaciones objetos y productos hacen ciertas normas jurídicas.

Las diversas funciones de la Administración Pública pueden clasificarse estableciendo en primer lugar, las funciones teleológicas de las funciones instrumentales o mediales, las primeras se hallan orientadas al cumplimiento de los fines propios de la Administración; mientras que, las segundas serán aquellas funciones que la Administración ejercita para procurarse los medios con que llevar acabo sus objetivos. De acuerdo con este enfoque, la inspección se concebirá como una manera de proveerse la Administración de datos o informaciones sobre los que poder luego actuar y cumplir después los objetivos que se le hayan encomendado.

La Administración inspecciona en atención a algo, es decir como medio para la actuación de otro fin superior o distinto.

La motivación fundamental de la asignación y del ejercicio de estas funciones de inspección y control es, en todos los casos la seguridad. Pero el correcto ejercicio de las competencias de inspección y control, provoca una repercusión económica y social de carácter positivo, siempre y cuando se complementen con armonía los principios de agilidad en las actuaciones, confianza en la actividad de los agentes y fiabilidad de los procedimientos de supervisión y control.

Cuando hablamos de la actividad, función o potestad de inspección, estamos evocando implícitamente una actividad pública esto es, de titularidad pública.

La doctrina administrativista ha identificado potestad con toda acción administrativa que se presenta como ejercicio de un poder atribuido previamente por la Ley, por ella delimitado y construido y, en cuanto a la potestad de inspección procede directamente del Ordenamiento Jurídico conteniendo un carácter genérico y refiriéndose a un ámbito de actuación delimitado previamente. 
La potestad de inspección pues, debido a su especial relevancia, ha de hallarse expresamente atribuida a las Administraciones por el Ordenamiento jurídico.

La función inspectora ha sido definida por la doctrina administrativista además, como una función claramente preparatoria de la decisión de los órganos administrativos activos o decisorios y, constituye una pieza muy importante para lograr el cumplimiento de la legalidad.

Toda función inspectora tiene dos vertientes, por un lado una función de vigilancia que con carácter preventivo procura el cumplimiento de la legislación y una actividad de constatación de los incumplimientos que se detecten con la consiguiente incoación de los expedientes correspondientes.

Además de la función de inspección que la Administración tiene atribuidas sobre materias de su competencia hay que señalar por otra parte que allí donde existan facultades de coordinación de la Administración, tendrá ésta además la potestad inspectora sobre esa coordinación consistente en vigilar el ejercicio de las actividades susceptibles de tal coordinación.

La Ley de prevención y control integrados de la contaminación exige que los resultados de las actuaciones de control e inspección se pongan a disposición del publico, sin más limitaciones que las establecidas en la legislación sobre el derecho a la información en materia de medio ambiente, debiendo entenderse incluida en esta limitación la normativa sobre protección de datos personales.

\section{SISTEMA DE INFRACCIONES Y SANGIONES}

También se establece un sistema de infracciones y sanciones sin perjuicio de las que establezca, en su caso, la legislación estatal específica y la autonómica.

Todo sistema administrativo de sanciones configura la actividad material de inspección con la consecuente instrucción de los expedientes como un todo formado por dos facetas de la misma función que es la competencia inspectora sobre una materia concreta.

El régimen de control ambiental, fundamentado tanto en una actividad previa de prevención como en una actividad de vigilancia y verificación del 
cumplimiento de la Ley ha de ser complementado con una actividad sancionadora que castigue los incumplimientos detectados.

El principio de legalidad de la actividad sancionadora exige que las infracciones y sanciones estén previstas en una norma con rango de Ley, no pudiéndose crear otras figuras de infracción mediante normas con categoría reglamentaria.

El problema en la normativa reguladora de las infracciones medioambientales puede estribar en la interpretación de algunos términos empleados para configurar los tipos cuya valoración no resulta siempre fácil.

La Ley de prevención y control integrados de la contaminación, regula el régimen de infracciones y sanciones dentro del Título IV dedicado a la Disciplina ambiental.

Por lo que se refiere a los sujetos responsables hemos de entender que, lo serán las personas físicas o jurídicas que cometan las infracciones aún cuando las mismas se hallen integradas en asociaciones temporales o comunidades de bienes sin personalidad.

La responsabilidad en materia de disciplina medioambiental que esta Ley regula es de naturaleza administrativa no excluyéndose la de otro orden si hubiere lugar a ella. Por ejemplo en los casos en que se considere que el supuesto acto infractor, pudiera ser constitutivo de delito o falta la administración dará traslado del tanto de culpa al Ministerio Fiscal, quedando suspendida entre tanto la tramitación del procedimiento administrativo sancionador. En caso de que no se apreciara existencia de delito o falta, el órgano administrativo competente continuará el expediente sancionador por otra parte los hechos declarados probados en la resolución judicial vincularán al órgano administrativo.

\section{Medidas provisionales}

Respecto a las medidas provisionales la Ley dispone que cuando se haya indicado un procedimiento sancionador, podrán acordarse, entre otras, alguna de las siguientes medidas provisionales:

a) Medidas de corrección, seguridad o control que impidan la continuidad en la producción del riesgo del daño.

b) Precintado de aparatos o equipos.

c) Clausura temporal, parcial o total de las instalaciones. 
d) Parada de las instalaciones.

e) Suspensión temporal de la autorización para el ejercicio de la activi$\mathrm{dad}^{34}$.

La adopción de estas medidas ha de ser motivada y cuando se estime preciso, se adoptarán dando razón de su proceder. El acuerdo y su motivación han de ser recogidos por escrito dando el traslado del mismo a los interesados.

Las medidas provisionales han adoptarse con base en un juicio de razonabilidad y escogiendo las que perjudiquen lo menos posible la situación jurídica del administrado. De todos modos deberán ser confirmadas, modificadas o levantadas acordándose, en su caso, la iniciación del procedimiento sancionador.

Los bienes aprehendidos habrán de ser liberados previa constitución de fianza u otro tipo de garantía financiera legalmente prevista cuya cuantía será fijada por el órgano competente, no pudiendo exceder del importe de la sanción que pudiera corresponder por la infracción o infracciones cometidas.

Los gastos derivados de la adopción de las medidas cautelares serán a cargo de imputado.

La validez del régimen sancionador medioambiental se hace depender como hemos señalado de los principios de legalidad y tipicidad respecto a las infracción y sanciones aplicables. Ambos principios están conectados, en cuanto a que la tipificación presupone la predeterminación normativa de las conductas ilícitas y del alcance de la sanción dentro de los márgenes establecidos por el legislador.

La potestad sancionadora en este ámbito se sitúa entre dos parámetros, el respeto a los derechos fundamentales a los que la actividad sancionadora pudiera afectar y, el inevitable castigo de las conductas contrarias a la Ley.

De la adecuada conjunción de ambos polos dependerá la eficacia del sistema que pretenda poner fin a la impunidad de las infracciones medioambientales.

\footnotetext{
${ }^{34}$ Estas medidas podrán ser acordadas antes de iniciarse el procedimiento administrativo sancionador en las condiciones establecidas en el artículo 72.2 de la Ley 30/1992 de 26 de noviembre de Régimen jurídico de las Administraciones Públicas y del Procedimiento administrativo Común.

Artículo 72.2 "No se podrán dictar medidas provisionales que puedan causar perjuicio de difícil o imposible reparación a los interesados o que impliquen violación de derechos amparados por las leyes".
} 


\section{Infracciones}

La Ley, aborda el tratamiento de las infracciones en este ámbito acalarando que las infracciones en materia de prevención y control integrados de la contaminación se establecen sin perjuicio de las que la normativa estatal sectorial o la de las Comunidades Autónomas pueda establecer.

Realiza una clasificación de las infracciones en función de su gravedad distinguiendo las muy graves, graves y leves.

I) Constituyen infracción muy grave:

a) El ejercicio de la actividad o su modificación sustancial sin haber obtenido la preceptiva autorización ambiental integrada ${ }^{35}$.

b) El incumplimiento de las condiciones que figuren en la Autorización ambiental integrada ${ }^{36}$.

c) El incumplimiento de obligaciones derivadas de las medidas provisionales adoptadas.

d) El ejercicio de la actividad incumpliendo obligaciones normativas (notificación y registro por las Comunidades Autónomas) ${ }^{37}$.

II) Constituyen infracciones graves:

a) El ejercicio de la actividad o su modificación sustancial sin la autorización ambiental sin que se haya producido daño o deterioro para el medio ambiente o sin que se haya puesto en peligro grave la seguridad o salud de las personas.

b) El incumplimiento de las condiciones establecidas en la autorización ambiental integrada sin daños ni peligro.

c) El ocultamiento o alteración maliciosos de la información exigida en los procedimientos regulados por la Ley.

d) La Transmisión de la titularidad de la autorización sin comunicarlo a la Administración competente.

e) La omisión de comunicación a la Administración de las modificaciones.

f) La omisión de notificación a la Administración de incidentes o accidentes de naturaleza medioambiental.

35 Siempre que se haya producido daños o deterioro grave para el medio ambiente o se haya puesto en peligro grave la seguridad o salud de las personas.

${ }^{36}$ En los mismos supuestos que la nota anterior.

${ }^{37}$ En iguales supuestos. 
g) El impedimento, retraso u obstrucción de la actividad de control. Hemos de señalar que se trata de tres tipos diferentes de actividad que por lo general se califican con diferente gravedad por las normas sancionadoras existentes.

h) El ejercicio de la actividad incumpliendo las obligaciones fijadas en la normativa reguladora sobre esta materia.

III) Constituyen infracciones leves:

a) La omisión de notificaciones preceptivas a las Administraciones Públicas siempre que no se haya derivado daño ni peligro.

b) El incumplimiento de las prescripciones establecidas en la Ley o sus normas de desarrollo siempre que no estuviera tipificado como infracción muy grave o grave.

\section{Sanciones}

Las infracciones establecidas en la Ley dan lugar a la aplicación de las siguientes sanciones:

I) En caso de infracción muy grave:

- Multa de 200.001 hasta 2.000.000 de euros.

- Clausura definitiva, total o parcial de las instalaciones.

- Clausura temporal, total o parcial de las instalaciones por un periodo no inferior a dos años ni superior a cinco.

- Inhabilitación para el ejercicio de la actividad por un periodo no inferior a un año ni superior a dos.

- Revocación de la autorización o suspensión de la misma por tiempo no inferior a un año ni superior a cinco.

- Publicación de las sanciones una vez que sean firmes así como los nombres, apellidos o razón social de los responsables y la índole y naturaleza de las infracciones.

II) En caso de infracción grave:

- Multa desde 20.001 hasta 200.000 euros.

- Clausura temporal, total o parcial, de las instalaciones por un periodo máximo de dos años.

- Inhabilitación para el ejercicio de la actividad por un periodo máximo de un año.

- Revocación de la autorización o suspensión de la misma por un periodo máximo de un año. 
III) En caso de infracción leve:

- Multa de 20.000 euros.

Como cláusula general aplicable a los casos de multa dispone la Ley que cuando la cuantía de la multa resulte inferior al beneficio obtenido por la comisión de la infracción, la sanción será aumentada, como mínimo, hasta el doble del importe en que se haya beneficiado el infractor ${ }^{38}$.

La Ley establece la obligación de guardar la debida adecuación entre la gravedad del hecho constitutivo de la infracción y la sanción aplicada enumerando una serie de criterios de graduación que deberán tenerse en cuenta para la aplicación de las sanciones:

a) La existencia de intencionalidad o reiteración. Factores subjetivos que hacen referencia al dolo y reiteración en la comisión de la misma infracción por parte del responsable de la infracción.

b) Los daños causados al medio ambiente o salud de las personas o el peligro creado para la seguridad de las mismas. Factores objetivos de resultado.

c) La reincidencia por comisión de más de una infracción tipificada por la Ley, siempre que así se haya declarado por resolución firme.

d) El beneficio obtenido por el responsable con la comisión de la infracción. De esta manera se quiere impedir la permanencia de ciertas conductas fundamentadas en el superior coste que a veces ha supuesto el cumplimiento de la ley que el abono de las sanciones económicas por su incumplimiento.

Por otra parte hemos de mencionar el principio de non bis in idem al establecerse la imposibilidad de sancionar los hechos que hubieran sido sancionados penal o administrativamente, en los casos en que se apreciase identidad de sujeto, hecho y fundamento. Por otra parte dispone la Ley que cuando por unos mismos hechos y fundamentos jurídicos, el infractor pudiese ser sancionado con arreglo a esta Ley y a otra u otras leyes que fueran de aplicación, sólo se le impondrá la sanción de mayor gravedad ${ }^{39}$.

Para el cómputo de los plazos de prescripción de infracciones y sanciones se estará a lo dispuesto en la Ley 30/1992 de 26 de noviembre de la Ley de Ré-

\footnotetext{
38 Artículo 32 de la Ley.

${ }^{39}$ Artículo 34 concurrencia de sanciones.
} 
gimen Jurídico de las Administraciones Públicas y del Procedimiento Administrativo común ${ }^{40}$.

En los casos de infracciones continuadas el plazo comenzará a contar desde el momento de la finalización de la actividad o del último acto con el que la infracción se consuma. En el caso de que los hechos o actividades constitutivos de infracción fueran desconocidos por carecer de signos externos, dicho plazo se computará desde que estos se manifiesten.

Además de la sanción que se imponga la Ley establece para el infractor la obligación de reposición o restauración de las cosas al estado anterior a la infracción cometida, así como en su caso al abono de la indemnización por daños y perjuicios causados que se determinará en vía administrativa. Para hacer efectiva esta obligación la Administración podrá acordar la imposición de multas coercitivas cuya cuantía no deberá superar el tercio de la multa prevista para el tipo de infracción cometida.

\section{PROCEDIMIENTO SANCIONADOR}

En el procedimiento sancionador en materia pesquera es de aplicación lo dispuesto en el Título IX de la Ley 30/1992 de 26 de noviembre de Régimen jurídico de las Administraciones Públicas y del Procedimiento Administrativo Común, así como el Reglamento del procedimiento para el ejercicio de la potestad sancionadora ${ }^{41}$.

El desarrollo del procedimiento sancionador administrativo en esta materia parte de la denuncia de la comisión de posibles infracciones, de los agentes encargados de la vigilancia de la actividad.

${ }^{40}$ Art. 133.2 "El plazo de prescripción de las infracciones comenzará a contarse desde el día en que la infracción se hubiera cometido.

Interrumpida la prescripción la iniciación, con conocimiento del interesado, del procedimiento sancionador, reanudándose el plazo de prescripción si el expediente sancionador estuviera paralizado durante más de un mes por causa no imputable al presunto responsable".

3 "El plazo de prescripción de las sanciones comenzará a contarse desde el día siguiente a aquel en que adquiera firmeza la resolución por la que se impone la sanción.

Interrumpirá la prescripción la iniciación con conocimiento del interesado, del procedimiento de ejecución, volviendo a transcurrir el plazo si aquel está paralizado durante más de un mes por causa no imputable al infractor".

${ }^{41}$ El Reglamento para el ejercicio de la potestad sancionadora aprobado por Real Decreto 1398/1993 de 4 de agosto (BOE de 9 de agosto). 
Estas autoridades harán constar en el acta de denuncia los hechos que consideren constitutivos de infracción.

Recibida la notificación, el instructor del procedimiento incoará el correspondiente expediente administrativo, redactando el acuerdo de inicio en el que se hará constar:

- La identificación de los presuntos responsables.

- Los hechos que motivan el procedimiento.

- El órgano competente para la resolución

- La práctica de las diligencias previas.

- Y La indicación del derecho a formular alegaciones y audiencia en el procedimiento.

El acuerdo de inicio se comunica al interesado para que alegue lo que considere oportuno.

Recibidas las alegaciones el instructor del expediente llevará a efecto la práctica de la prueba (declarativa, testifical, documental y pericial)

Concluida la fase de prueba el instructor redactará una propuesta de Resolución en que se describirán los hechos que se consideren probados su calificación jurídica determinándose la infracción y proponiéndose sanción.

Este propuesta de resolución se notifica a los interesados poniéndoles de manifiesto el expediente para que aleguen lo que consideren oportuno.

Los procedimientos concluyen con la fase de Resolución donde la autoridad competente en cada caso acuerda o bien sobreseer el expediente o la imposición de la correspondiente sanción.

\section{EPÍlOGO}

Una vez examinados los diferentes aspectos de la ley nos resta señalar algunas cuestiones adicionales que el texto incluye.

Esta Ley modifica en sus Disposiciones finales, el Texto refundido de la Ley de Aguas, la Ley 10/1998 de 21 de abril de Residuos y la Ley 38/1972 de 22 de diciembre de protección del ambiente atmosférico. 
Para finalizar mencionaremos los cuatro anejos que acompañan a la Ley:

1 Categorías de actividades e instalaciones contempladas en el artículo 2.

2 Normas contempladas en el apartado 2 del artículo 7 de la Ley.

3 Lista de las principales sustancias contaminantes que se tomarán obligatoriamente en consideración si son pertinentes para fijar valores límite de emisiones.

4 Aspectos que deben tenerse en cuenta con carácter general o en un supuesto particular cuando se determinen las mejores técnicas disponibles definidas en el artículo 3.ñ), teniendo en cuenta los costes y ventajas que pueden derivarse de una acción y los principios de precaución y prevención.

\section{BIBLIOGRAFÍA}

ALONSO GARCÍA, Derecho ambiental de la comunidad Europea. Madrid: 1993.

La política ambiental comunitaria y el significado de la aprobación del Tratado de la Unión Europea para la misma REVISTA DE ADMINISTRACIÓN PÚBLICA núm. 140.

BELLOCH Y DE MIGUEL, Estudio comparado de la organización administrativa del medio ambiente. Madrid: 1979.

DOMPER FERRANDO Javier El medio Ambiente y la intervención administrativa en las actividades clasificadas Madrid: 1992.

ESTEVE PARDO Derecho del medio ambiente y Administración Local. Madrid: 1996.

FERNÁNDEZ DE CASADEVANTE, La protección del medio ambiente en Derecho internacional, derecho comunitario y Derecho español. Vitoria: 1991.

LOPERENA ROTA Los principios de Derecho ambiental Madrid 1998.

LÓPEZ BUSTOS, La organización administrativa del medio ambiente. Madrid: 1992.

LÓPEZ RAMÓN, Caracteres del derecho comunitario ambiental REVISTA ESPAÑOLA DE ADMINISTRACIÓN PÚBLICA NÚM. 142. 
MANTECA VALDELANDE Proyecto de Ley de control integrado de la contaminación LA LEY núm. 5563 de 11.6.2002.

MARTÍN MATEO Ramón, Manual de Derecho Ambiental Madrid: 1995.

MARTÍN MATEO Tratado de Derecho Ambiental 3 vols. Madrid: 1991,1992 y 1997.

MIGUEL PERALES Derecho español del Medio ambiente. Madrid 2000.

ORTEGA ÁLVAREZ Y OTROS Lecciones de Derecho del medio ambiente. Valladolid: 1998.

PEDERNAL PECES Europa y el medio ambiente. Madrid: 1987.

POMED SÁNCHEZ, La protección del medio ambiente como función estructural del estado en el seno de la Unión Europea: entrecruzamientos competenciales. REVISTA ESPAÑOLA DE ADMINISTRACIÓN PÚBLICA Núm. 98. 